\section{Metabolic response of Adenocalymma peregrinum during regeneration of the aerial parts}

\author{
Vanessa Samudio dos Santos, ${ }^{1}$ \\ Maria Rita Marques, ${ }^{1}$ \\ Dayana Rubio Gouvea, ${ }^{2}$ \\ Norberto Peporine Lopes, ${ }^{2}$ \\ Vespasiano Borges de Paiva Neto, ${ }^{3}$ \\ Carlos Alexandre Carollo ${ }^{1}$ \\ ${ }^{1}$ Center of Biological and Health Sciences, \\ Federal University of Mato Grosso do \\ Sul, Campo Grande; ${ }^{2}$ NPPNS-School \\ of Phamarceutical Sciences of Ribeirão \\ Preto, University of São Paulo, Ribeirão \\ Preto; ${ }^{3}$ Campus of Chapadão do Sul - \\ CPCS, Federal University of Mato Grosso \\ do Sul, Chapadão do Sul, Brazil
}

\begin{abstract}
Adenocalymma peregrinum, popularly known as ciganinha, is an aggressive pasture invader. This species has a vegetative propagation mechanism that includes aerial latent buds and subterranean stalks activated by cuts and other lesions. In the present study, we evaluated the levels of cytokinins and secondary metabolites in $A$. peregrinum during regeneration of the aerial part. Plants used in this experiment were established in the field and were cut at intervals of five days until the $25^{\text {th }}$ day. The regeneration of the cut plants started on the $10^{\text {th }}$ day after the first cut. Among observed compounds, only kinetin, allantoin and the iridoide 6 - $\beta$-hydroxyipolamiide were detected at adequate levels for comparative evaluation. The maximum levels of these compounds coincided with the beginning of regeneration in these plants, indicating the involvement of these compounds in the regeneration process.
\end{abstract}

\section{Introduction}

Environments altered by humans facilitate invasions by wild or exotic species, resulting in economic and environmental losses. ${ }^{1,2}$ Adenocalymma peregrinum (Miers) L.G. Lohmann (Bignoniaceae) (popularly known as ciganinha), is characterized by the ability to disperse rapidly following cutting by animals or fires. This mechanism is made possible by vegetative propagation that includes aerial latent buds and subterranean stalks. ${ }^{3}$

The regeneration of $A$. peregrinum is efficient and is mediated by biochemical mecha- nisms specifically developed to counter environmental stresses, ${ }^{4}$ thereby enabling this species to invade pastures and cause serious damages to local husbandry.

In plants incapable of fixating atmospheric nitrogen, including some species of the Bignoniaceae family, compounds similar to allantoin have been shown to be adequate alternative sources of nitrogen. ${ }^{5}$ Grassi et al. ${ }^{6}$ isolated large amounts of allantoin from $A$. peregrinum and suggested that this ureide could be used to establish a competitive advantage over other species.

Cytokinins have a key role in the differentiation and regeneration of plants, namely, by inducing cellular division, proliferation and morphogenesis of the aerial part. ${ }^{7}$ This phenomenon may also be related to adaptation strategies and the rapid development of $A$. peregrinum. To analyze compounds present at very low levels, such as plant hormones, previous literature has described the use of methods based on liquid chromatography (e.g., studies by Peres et al. ${ }^{8}$ and Zhang et al. ${ }^{9}$ ) and liquid chromatography combined with mass spectrometry (HPLC-MS) using electrospray ionization (e.g., a study by De Vos et al.). ${ }^{10}$ These methods have been used in several plant hormone studies, allowing simultaneous quantification of several compounds. ${ }^{11}$

Therefore, the objective of this study was to evaluate the levels of cytokinins and secondary metabolites in A. peregrinum during regeneration of the aerial parts.

\section{Materials and Methods}

\section{Material collection for analysis}

Plant material was collected in Brazil, Campo Grande, Mato Grosso do Sul (20³7'56,30”S; $\left.54^{\circ} 34^{\prime} 14,00^{\prime \prime} W\right)$. For the botanical identification, fertile material of $A$. peregrinum was herborized, identified and deposited in the CGMS herbarium of UFMS under number 33487.

The aerial parts of adult plants established in the field were used for analysis. The aerial parts were removed leaving $10 \mathrm{~cm}$ of above ground material. Stalk samples collected for analysis left $5 \mathrm{~cm}$ of the superior part near the previously made cut. The stalk samples were collected at $0,5,10,15,20$ and 25 days after the removal of the aerial part, and each group consisted of seven specimens. The samples were frozen in liquid nitrogen at the moment of collection and stored at $-80^{\circ} \mathrm{C}$ until use.

\section{Extraction and analytical methods for the evaluation of cytokinins and secondary metabolites \\ The following HPLC-grade solvents were used in the extraction and resolubilization}

Correspondence: Carlos Alexandre Carollo, Center of Biological and Health Sciences, Federal University of Mato Grosso do Sul, 79070-900 Campo Grande, MS, Brazil.

Tel.: +55.067.3345.7366 - Fax: +55.067 .3345 .7305$ E-mail: carlos.carollo@ufms.br

Key words: ciganinha, cytokinins, pasture invaders, secondary metabolites.

Contributions: VSS running laboratory and experimental work; DRG and NPL conducted the analytical studies; VSS and CAC analyzed data and drafted the paper; MRM, VBPN and CAC designed the study and supervised the laboratory work; MRM, NPL, VBPN, CAC contributed to critical reading of the manuscript.

Acknowledgments: the authors would thank the "Fundação de Apoio ao Desenvolvimento do Ensino, Ciência e Tecnologia do Estado de Mato Grosso do Sul" (FUNDECT) for the research grant given to the first author; the "Coordenação de Aperfeiçoamento de Pessoal de Nível Superior" (CAPES), "Fundação de Amparo à Pesquisa do Estado de São Paulo" (FAPESP) and the "Instituto Nacional de Ciências e Tecnologia em Áreas Úmidas" (INAU) for the financial support. To UFMS for the logistical and financial support.

Conflict of interest: the authors declare no potential conflict of interests.

Funding: this paper was funded by "Fundação de Amparo à Pesquisa do Estado de São Paulo" (FAPESP) and the "Instituto Nacional de Ciências e Tecnologia em Áreas Úmidas" (INAU).

Received for publication: 20 February 2014.

Revision received: 12 May 2014.

Accepted for publication: 19 May 2014.

This work is licensed under a Creative Commons Attribution NonCommercial 3.0 License (CC BYNC 3.0).

(OCopyright V. Samudio dos Santos et al., 2014 Licensee PAGEPress srl, Italy

International Journal of Plant Biology 2014; 5:5363 doi:10.4081/pb.2014.5363

tests: methanol, ethanol, N-propanol and formic acid. The analytical method was optimized for the comparative evaluation of the cytokinins and secondary metabolites present in the samples (data not shown).

For metabolite extractions, $50 \mathrm{mg}$ of plant material was added to $2 \mathrm{~mL}$ of ethanol/ $\mathrm{H}_{2} \mathrm{O}$ / formic acid $(9: 1: 0.1 \mathrm{v} / \mathrm{v} / \mathrm{v})$. The samples were extracted for 15 minutes in an ultrasonic bath. Following extraction, $1.5 \mathrm{~mL}$ of the supernatant was removed and added to $500 \mu \mathrm{L}$ of hexane. After 10 minutes, the hexane was removed, and the supernatant was dried in a speed vacuum 
concentrator for 10 hours at a temperature of $45^{\circ} \mathrm{C}$. Resolubilization of the sample was achieved by adding $300 \mu \mathrm{L}$ of the mobile phase, comprised of acetonitrile/ $\mathrm{H}_{2} \mathrm{O} /$ formic acid $(1: 1: 0.1 \mathrm{v} / \mathrm{v} / \mathrm{v})$. All of the extractions were performed in triplicate, and the injection volume was $5 \mu \mathrm{L}$.

For confirmation of the compounds, we used high resolution data obtained with the UFLC Shimadzu equipment (pump model LC $20 \mathrm{AD}$, automatic injector SIL 20 A HT, CBM 20A controller, DAD detector model SPD-M 20A) coupled to a UltroTOF-Q hybrid high-resolution mass spectrometer (Bruker Daltonics Billerica, MA, USA) operating under negative or positive ionization. For chromatographic separation, a C18 column $(25 \times 4.6 \mathrm{~cm}, 5$ micrometers, Sigma Aldrich) was used with a pre-column of the same material. For the comparative evaluation of the compounds, low resolution analyses were performed on an ACQUITY UPLC-DAD-MS/MS Waters system (column: ACQUITY $1.7 \mu \mathrm{m}$ EBH (Ethylene Bridged Hybrid) C18, with dimensions of $2.1 \times 50 \mathrm{~mm})$.

The mobile phase was comprised of ultrapure water (Milli-Q, Millipore ${ }^{\circledR}$ ) (phase A) and acetonitrile (phase B), both containing $0.1 \%$ formic acid. The temperature of the column was held at $40^{\circ} \mathrm{C}$, and the samples were conditioned to $20^{\circ} \mathrm{C}$. The flow rate of the mobile phase was $0.3 \mathrm{~mL} / \mathrm{min}$, and the injection volumes varied from 2 to $5 \mu \mathrm{L}$, depending on the concentration of the sample to be analyzed. Samples were filtered through disposable membranes with a $13 \mathrm{~mm}$ diameter and 0.22 $\mu \mathrm{m}$ pores. The gradients of mobile phase ( $\%$ phase B) were as follows: $3 \%$ for 5 min. followed by $4 \%$ for $3 \mathrm{~min}$., $5 \%$ for $1 \mathrm{~min}$., 100\% for $2.50 \mathrm{~min}$. and $3 \%$ for $2.10 \mathrm{~min}$.

Data acquisition and processing were performed using DataAnalysis 4.0 software for high resolution analysis and MassLynx 4.1.5 for low resolution analysis. The analyses monitored allantoin, $6 \beta$-hydroxyipolamiide and seven cytokinins: isopentenyladenine, kinetin, benzyladenine, isopentenyladenosine, zeatin ribose, dihydrozeatin ribose and zeatin-9-glucoside.

\section{Data analysis}

The data were submitted to statistical analysis by an ANOVA test followed by a Tukey test. The statistical analyses were performed using Minitab 16.

\section{Results}

The compound of mass $\mathrm{m} / z 405.1886$ detected in the analysis was identified as glycosylated iridoid $6 \beta$-hydroxyipolamiide. This iridoid has previously been isolated from leaf extracts of $A$. peregrinum. ${ }^{6}$ Due to the lack of data per- taining to the fragments generated by impact collision of electrons of this compound, we proposed a fragmentation pattern of this iridoid in this study (Figure 1). The initial compound undergoes dehydration at the source in position 5 and then fragments, losing the glucopyranoside group and thus generating the peak at $m / z$ 193.0495. This compound then either dehydrates, generating the peak at $\mathrm{m} / \mathrm{z}$ 175.0390 , or loses the $\boldsymbol{O}$-methyl group, forming a fragment at $m / z 165.0549$.

The regeneration of $A$. peregrinum was initiated 10 days after cutting, and by the $25^{\text {th }}$ day, total recomposition of the aerial parts was evident.

Nine compounds, with the fragments and retention times described in Table 1 , were detected.

Cytokinins were confirmed based on a study by Bartok et al. ${ }^{12}$ In the UPLC-DAD-MS/MS analysis, the concentrations of some cytokinins were below the quantification level of the equipment (signal/noise less than 10 times). Thus, these compounds were only classified as present or absent in the experiments. Only allantoin, kinetin and $6 \beta$-hydroxyipolamiide were detected at adequate levels for comparative evaluation.

The plants whose aerial parts were removed in the field showed significant differences in relation to the concentration of kinetin between the $5^{\text {th }}$ and $15^{\text {th }}$ day after removal of the aerial part. Maximum concentrations of allantoin and $6 \beta$-hydroxyipolamiide coincided with the start of the regeneration process in the plants, but statistical analyses (P-value of less than 0.05) did not exhibit significant differences among the regeneration periods of the aerial parts (Figure 2).

Through mass spectrometric analysis, we observed a higher recruitment of kinetin relative to allatoin and $6 \beta$-hydroxyipolamiide during the regeneration period of the aerial part.

\section{Discussion}

The compound 6 $\beta$-hydroxyipolamiide has an important role in decreasing the growth rate of many generalist herbivore insects by inhibiting their feeding. ${ }^{13}$ Therefore, this compound could provide additional protection for the species during their recovery.

Natural as well as anthropogenic disturbances to the aerial parts of plants stimulate vegetative growth. ${ }^{14}$ For this growth and for the formation of new tissues to occur, cellular divisions stimulated by plant hormones are

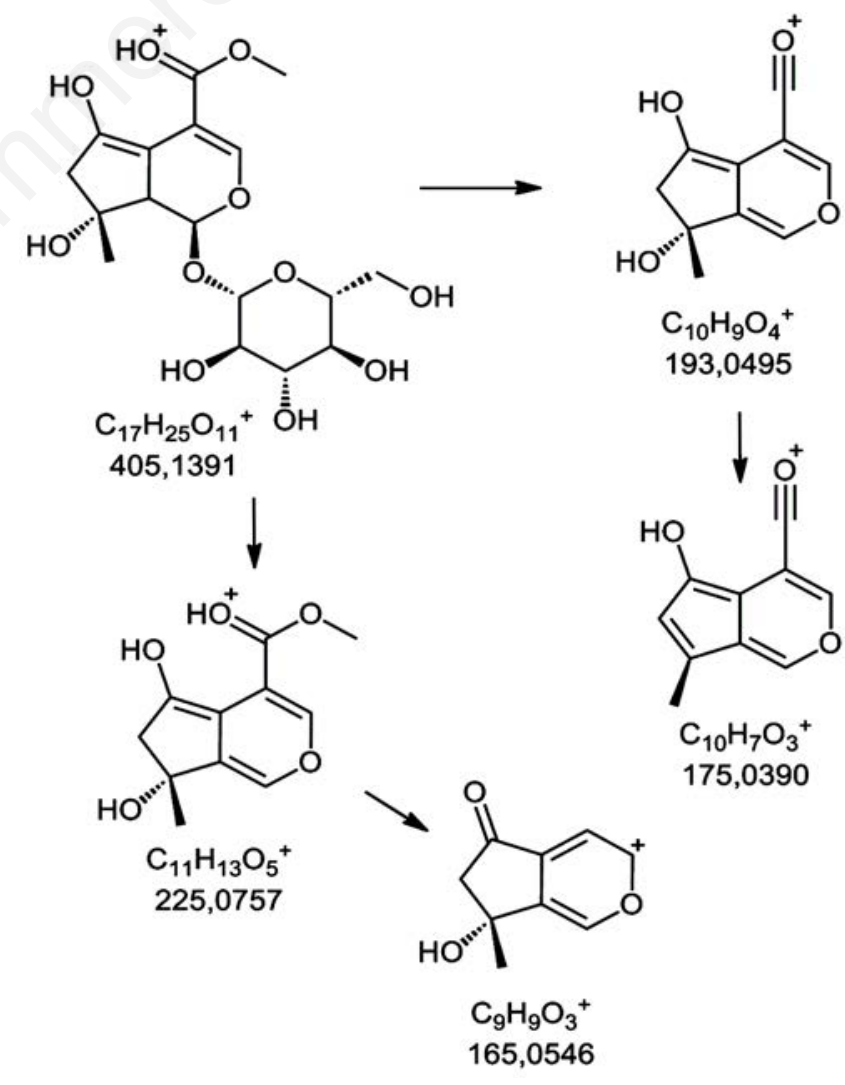

Figure 1. Proposed fragmentation of $6 \beta$-hydroxyipolamiide. 
Table 1. Compounds, abbreviations, molecular masses, retention times and compound fragments observed by mass spectrometry.

\begin{tabular}{|c|c|c|c|c|c|}
\hline Common name & Abbreviation & $\begin{array}{l}\text { Molecular } \\
\text { mass }\end{array}$ & $\begin{array}{l}\text { Retention } \\
\text { time (min) }\end{array}$ & \multicolumn{2}{|c|}{$\begin{array}{l}\text { Ion product } \\
(\mathrm{m} / \mathrm{z})\end{array}$} \\
\hline Allantoin & ALN & 159.0512 & 0.50 & 116 & - \\
\hline Zeatin-9-glucoside & {$[9 \mathrm{G}] \mathrm{Z}$} & 382.1721 & 0.52 & 220 & 136 \\
\hline Zeatin ribose & {$[9 \mathrm{R}] \mathrm{Z}$} & 352.1615 & 0.58 & 220 & 136 \\
\hline Dihydrozeatin ribose & $(\mathrm{diH})[9 \mathrm{R}] \mathrm{Z}$ & 354.1771 & 1.65 & 222 & 136 \\
\hline Isopentenyladenine & iP & 204.1243 & 3.67 & 136 & 119 \\
\hline Kinetin & KIN & 216.0879 & 4.79 & 148 & 81 \\
\hline Benzyladenine & BAP & 226.1087 & 6.24 & 91 & - \\
\hline $6 \beta$-hydroxyipolamiide & - & 405.1385 & 6.41 & 193 & 175 \\
\hline Isopentenyladenosine & [9R]iP & 336.1666 & 9.04 & 136 & 204 \\
\hline
\end{tabular}
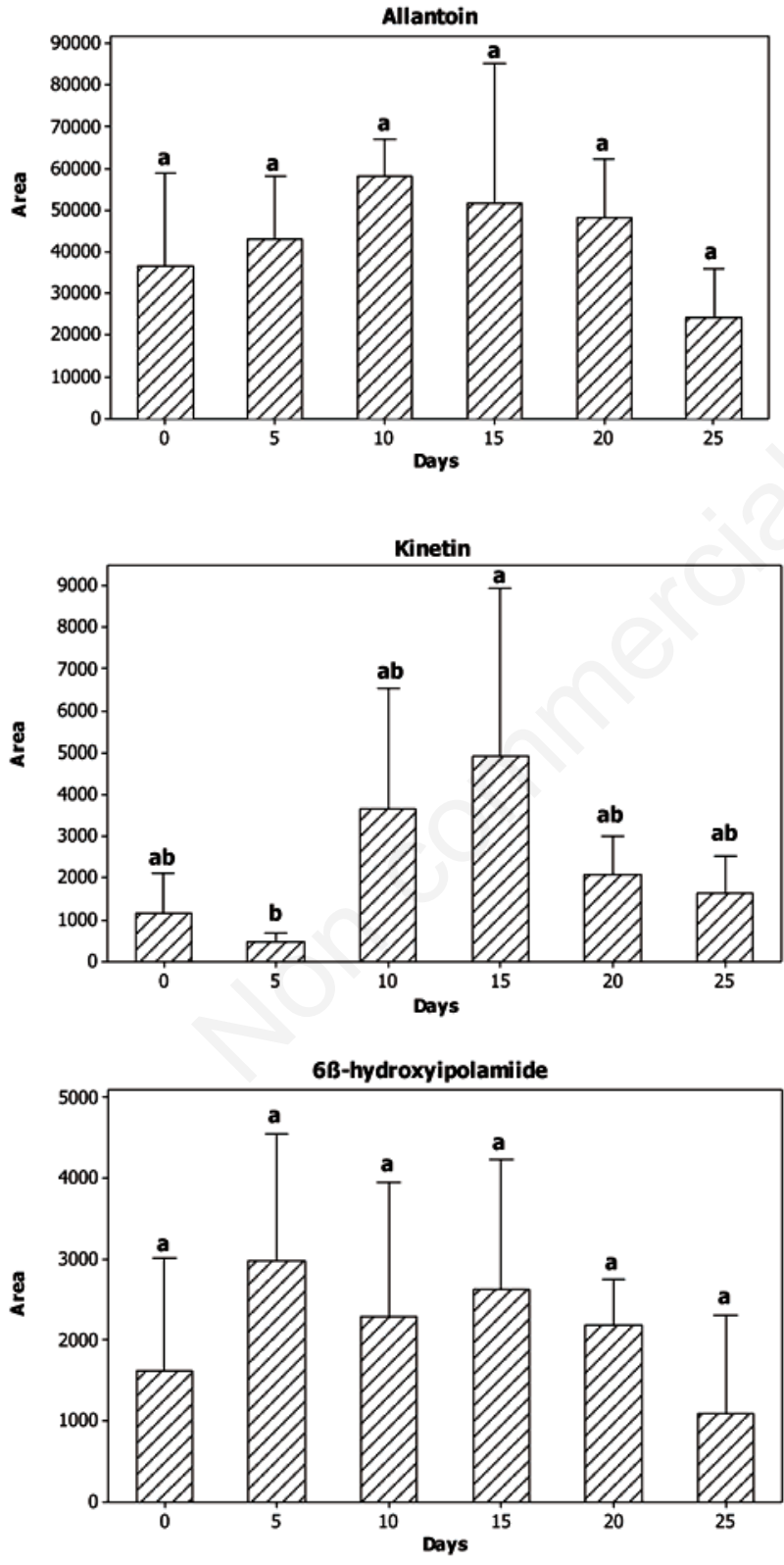

Figure 2. Areas of the peaks corresponding to allantoin, kinetin and 6 -hydroxyipolamiide in the HPLC/MS chromatogram of the stalk samples of Adenocalymma peregrinum at different periods after removal of the aerial parts of plants established in the field. Same letters indicate values that do not differ from each other by the Tukey test with a $5 \%$ probability of error. necessary. ${ }^{7}$

The removal of the aerial part of plants stimulated rapid regeneration. During this period we observed a higher concentration of kinetin (Figure 2), which likely contributed to the recomposition of the aerial part by inducing the occurrence of cellular divisions.

The concentrations of cytokinins in this species were extremely low, confirming the concentration data of these hormones in plants reported by Peres et al. ${ }^{15}$

In a study performed by Lopes et al. ${ }^{16}$ on sprouting papayas with different cut heights of the aerial parts $(20,25$ and $35 \mathrm{~cm}$ from the plant's stem), a higher sprouting performance and bud size were observed in the plants cut 20 $\mathrm{cm}$ from the stem. The lower cut height promoted a higher proximity between the aerial part and the radicular system, causing rapid translocation of these compounds and elevated concentrations of cytokinins at the cut location in a shorter period of time. This effect likely explains the intensity and velocity of regrowth of plants considered to be invaders. At the moment they suffer a severe cut, these plants activate a mechanism of translocation of cytokinins to induce cellular division at the cut location for tissue regeneration.

In a study by Lopes et al. ${ }^{17}$ the methodology of cutting aerial branches of $A$. peregrinum already established in the field was used with the objective of comparing the growth rate and the concentration of ureides between plants with aerial cuts approximately $10 \mathrm{~cm}$ above ground and a control group (no cut). It was shown that in $A$. peregrinum, there was a translocation of a large quantity of ureides from the subterraneous stalk to the aerial part following the mechanical cut, in addition to an increase in concentration of these ureides some months after the cut, suggesting that these compounds contributed to the production of new plant tissues.

The studies analyzing the concentrations of ureides in seedlings of $A$. peregrinum have also confirmed the hypothesis established by Grassi et al. ${ }^{6}$ suggesting that a species produces and stores ureides in both the roots and the rhizome, and these are transported to other tissues of the plant; hence, this mechanism gives the species an advantage over other species, allowing it to establish as an invasive species.

The results of this study confirm that the damage caused to plants by disturbances in the plant tissues favors biochemical responses, such as those reported by Vázquez-Flota $e t$ $a l .{ }^{18}$ and that these mechanical damages can induce increases in concentrations of certain compounds in the plants, as in the case of kinetin. This increase is likely linked to the production of new tissues for the regeneration of the aerial part of the affected plant. 
Universidade Federal de mato Grosso do Sul, Brazil, 2009.

5. Desimone M, Catoni E, Ludewig U, et al. A novel superfamily of transporters for allantoin and other oxo derivatives of nitrogen heterocyclic compounds in Arabidopsis. Plant Cell 2002;14:847-56.

6. Grassi R, Resende U, Da Silva W, et al. Phytochemical study and evaluation of allelopathy in Memora peregrina, 'ciganinha', Bignoniaceae, an invading species in pastures in Mato Grosso do Sul, Brazil. Quim. Nova 2005;28:199-203.

7. Taiz L, Zeiger E. Fisiologia vegetal. 4th ed. Porto Alegre: Artmed; 2009. p 820.

8. Peres L, Amar S, Kerbauy G, et al. Effects of auxin, cytokinin and ethylene treatments on the endogenous ethylene and auxin-to-cytokinins ratio related to direct root tip conversion of Catasetum fimbriatum Lindl. (Orchidaceae) into buds. J Plant Physiol 1999;155:551-5.

1. Radford I, Cousens R. Invasiveness and comparative life-history traits of exotic and indigenous Senecio species in Australia. Oecologia 2000;125:531-42.

2 Suding K, Gross K, Houseman G. Alternative states and positive feedbacks in restoration ecology. Trends Ecol Evo 2004;19:46-53.

3. Nunes SG. Ciganinha. Memora peregrina (Miers) Sandw. Nova planta invasora de Pastagem. 1999. Available from: http:// www.cnpgc.embrapa.br/publicacoes/divulga/GCD35.html

4. Oliveira AMRD. Proteínas de defesa em folhas de Memora peregrina (Miers) Sandwith (Bignoniaceae). Uma Espécie invasora de pastagem. Thesis Dissertation,

9. Zhang Y, Zhu H, Guo L. [Process of iridoids in gardenia and its effect on relevant enzymes in vivo]. Zhongguo Zhong Yao Za Zhi 2012;37:269-73. [Article in Chinese].

10. De Vos RCH, Moco S, Lommen A, et al. Untargeted large-scale plant metabolomics using liquid chromatography coupled to mass spectrometry. Nat Protocols 2007;2: 778-91.

11. Ge L, Yong J, Tan S, Ong E. Determination of cytokinins in coconut (Cocos nucifera L.) water using capillary zone electrophoresis-tandem mass spectrometry. Electrophoresis 2006;27:2171-81.

12. Bartok T, Borcsok G, Komoroczy R, Sagi F. Characterization of cytokinins by electro- spray ionization and collision-induced dissociation mass spectrometry without precursor ion selection. J Mass Spectrom 1996;31:756-60.

13. Darrow K, Bowers MD. effects of herbivore damage and nutrient level on induction of iridoid glycosides in Plantago lanceolata. J Chem Ecol 1999;25:1427-40.

14. Nakamura M, Kagata H, Ohgushi T. Trunk cutting initiates bottom-up cascades in a tri-trophic system: sprouting increases biodiversity of herbivorous and predaceous arthropods on willows. Oikos 2006; 113:259-68.

15. Peres LEP, Mercier H, Kerbauy GB, Zaffari GR. Endogenous levels of IAA, cytokinins and ABA in a shootless orchid and a rootless bromeliad determined by means of HPLC and ELISA. Braz J Plant Physiol 1997; 9:169-76.
16. Lopes J, Coelho R, Bregonci I, et al. Shooting of papaya tainung 1 (Carica papaya L.) submitted the different heights of cut of the stem. Ciênc Agrotec 2008; 32:360-65.

17. Marchetti CR. Taxa de crescimento e dinâmica do metabolismo de nitrogênio de Memora peregrine, uma espécie invasora de astagens. Thesis dissertation. Universidade Federal de Mato Grosso do Sul, Brasil, 2006.

18. Vazquez-Flota F, Carrillo-Pech M, MineroGarcia Y, Miranda-Ham M. Alkaloid metabolism in wounded Catharanthus roseus seedlings. Plant Physiol Biochem 2004; 42:623-8. 